8. Платон. Кратил / Собрание сочинений. Т.1. СПБ.: Изд-во С.-Петербургского ун-та, 2006. - с. 421 500.

9. Плунгян В.А. Введение в грамматическую семантику: грамматические значения и грамматические системы. М.: РГГУ, 2011. - 672 с.

10. Ревзин И.И. Структура немецкого языка. М.:ОГИ, 2009. - 400 с.

11. УспенскийБ.А. EgoLoquens. Язык и коммуникативное пространство языка. 2-еизд. М.: РГГУ, 2012. $344 \mathrm{c.}$

12. Якобсон Р.О. Шифтеры, глагольные категории и русский глагол // Принципы типологического анализа языков различного строя. М.: Наука, 1972. - с. 95 - 113.

13. Duden. Die Grammatik. 7.Aufl. B.4. Mannheim: Dudenverlag, 2006. - 1343 S.

14. Eisenberg P. Grundriss der deutschen Grammatik. B.2: Der Satz. Stuttgart, Weimar: J.B. Melzer Verlag, 2013. $-535 \mathrm{~S}$.

15. Engel U. Deutsche Grammatik. 2. Aufl. München: IUDICIUM Verlag, 2009. - 485 S.

16. Engelen B. Schwierige sprachliche Strukturen. Aufsätze zur deutschen Grammatik. Frankfurt am Main: Peter Lang, 2010. - 217 S.

17. Griesbach H. Neue deutsche Grammatik. 5. Aufl. Berlin, München: Langenscheidt, 1990. - 424 S.

18. Haider H. The Syntax of German. Cambridge: CUP, 2011. - 371 p.

19. Meibauer J. et al. Einführung in die germanistische Linguistik. Stuttgart, Weimar: J.B. Metzler Verlag, 2002. $-364 \mathrm{~S}$.

20. Morgenthaler E. Kommunikationsorientierte Textgrammatik. Düsseldorf: Schwann Verlag, 1980. - 204 S.

21. Schmidt W. Grundfragen der deutschen Grammatik. Eine Einführung in die funktionale Sprachlehre. 6. Aufl. Berlin: Volk und Wissen Volkseigener Verlag, 1983. - 332 S.

22. Weinrich H. Textgrammatik der deutschen Sprach. 4. Aufl. Hildesheim, Zürich, New York: Georg Olms Verlag, 2007. - 1111 S.

23. Welke K. Valenzgrammatik des Deutschen. Eine Einführung. Berlin, New York: De Gruyter, 2011. - 343 S.

24. Zifonun G. et al. Grammatik der deutschen Sprache. B.1. Berlin, New York: De Gruyter, 1997. - 952 S.

\title{
Садыкова А.X. \\ Слова и фразы на английском языке без аналогов. Или «экстраординарность языка»
}

Чеченский Государственный Университет (Россия, Грозный)

doi: $10.18411 / s p c-26-11-2017-15$

idsp: 000001:spc-26-11-2017-15

\section{Аннотация}

Данная работа посвящена проблеме объяснения и перевода слов, фраз и концептов, которые не имеют культурных аналогов. Работа нацелена на то, чтобы лучше понимать культуру нации через богатство лексического состава.

Ключевые слова: экстраординарные слова, концепты, английский язык, культура.

\section{Annotation}

The work is devoted to the problem of explanation and translation of the words, phrases and concepts which do not have culture analogs. The work is devoted to better understanding the culture of the nation through the lexis.

Keywords: eccentricity of the language, concepts, English language, culture.

«Во многих языках одно слово может описывать огромную гамму чувств, и для его перевода на другой язык может потребоваться целая фраза»[3].

Любой язык можно сравнить с океаном - чем глубже заходишь, тем больше материала для изучения. И наша работа направлена на то, чтобы выявить и показать степень уникальности и глубины рассматриваемых языков. Так, одним из показателей уникальности языка, являются слова, которые не переводятся одним словом - их можно только объяснить. Далее будет приведен ряд примеров по каждому рассматриваемому в работе, языку 
Во многих языках есть слова, которые невозможно перевести. Они представляют собой настоящий кошмар даже для самых профессиональных переводчиков. Откуда же берутся такие слова?

Непереводимые слова называются реалиями языка (предметы, национальные особенности, исторические факты, не имеющие эквивалентов в других языках). Например, названия блюд (окрошка, гамбургер), имена писателей (Пушкин, Шекспир), предметы, попросту не существующие в других культурах — подобные слова невозможно перевести на другой язык.

Слова, которые сложно перевести на другой язык, сообщают нам о привычках и ценностях народа, а также о глубине воспринимаемых понятий:

a) показывают привычки народа;

б) указывают на глубину воспринимаемых понятий;

в) показывают ценности народа.

Ниже будет приведен ряд слов и фраз с английского языка, которые не имеют точных аналогов в других языках. Они показывают признаки самобытности и особенности привычек представителей данной культуры.

Что же делать переводчику с такими словами? Существует несколько вариантов:

1. Дать дефиницию, то есть объяснить, что означает данное слово сделать транслитерацию (spam-спам);

2. Привести приближенный, примерный перевод, который описывает предмет лишь частично (drugstore - аптека, хотя в американском drugstore помимо лекарств продают газеты, журналы, напитки. Поэтому фраза «Foodisawfulindrugstores» не должна переводиться как «В аптеках ужасная еда». В данном случае более уместно употребление слова «закусочная»).

В данной статье будет использоваться первый способ. Так как он максимально раскрывает понятие нового слова.

Bioaccessory (дословно -биоаксессуар) -«Если хочешь выглядеть хорошо, будь рядом с тем, кто выглядит нехорошо»- гласит английское шуточное выражение. Но, видимо, шутка переросла в реалий, так как для этого явления уже существует отдельное слово. Довольно часто можно увидеть двух девушек-подростков, одна из которых намного симпатичнее другой.

Closetmusic (дословно - чуланная музыка) - это музыка, которую скрывают как скелеты в шкафу. У каждого меломана есть песня, которая заставит своего хозяина чувствовать себя беззащитным и опозоренным, если ее услышат все остальные. К примеру, если у серьезного бизнесмена заиграет ДжастинБибер, это будет, как минимум, очень интересно.

Gobbledygook - данное слово обозначает «китайскую грамоту» или что-то очень непонятное. К примеру, если человек что-то бубнит себе под нос, или если человек говорит непонятным бюрократическим языком, пытаясь выглядеть очень умным.

Stage-phoning (дословно - постановочный звонок) -данная фраза описывает ситуацию, когда человек хвастается через несуществующий или специально подстроенный звонок. И мы «случайно» узнаем о его доме у моря и дорогой машине.

Brandalism (oтbranduvandalism) - составное слово, описывающее ситуацию, когда реклама и объявления кричат со стен улиц. Данное явление нередко встречается в больших городах с плотным населением.

Sibling - в английском языке есть слово, обозначающее родных брата или сестру. Слово «sibling» не имеет рода и может относиться как к сестре, так и к брату [3]. 
"Переводчик должен переводить не только с одного языка на другой, но и из одной культуры в другую» - говорит управляющий директор исследовательского агентства Югра Зилинске, которая долгое время работала переводчиком.

Так, журнал «Тіmes» специально перевел для своих читателей самые непереводимые слова в мире. Английские слова из данного списка будут приведены ниже.

В английском языке среди самых непереводимых слов оказались:

1.Googly-кэмбриджский словарь гласит, что это способ подать мяч в крикете, когда подающий рискует сломать ногу.

Почему данное слово оказалось в списке самых непереводимых слов? Просто потому, что в крикет играют не везде.

2. Слово «spam» достаточно быстро было заимствовано из английского языка. На данный момент мы употребляем данное слово, чтобы сказать о лишних рассылках и уведомлениях, заполняющих нашу электронную почту.

Слово «спам» - сложносокращенное слово, еще вернее - акроним. А вот образовано оно от spicedham, что в переводе означает «перченая ветчина» и «ветчина со специями». То есть это связка слов специи и ветчина, именно таков дословный перевод с английского языка.

Но история данного слова тянется еще с далекого 1937 года. Компания «Hormelfarms» выпустила в продажу фарш из не самого свежего мяса, которое скопилось на их фабрике. Консервы поставлялись во флот и даже военное ведомство, а их реклама достигала невероятных размеров. Хозяин разрекламировал продукт из-за того, что никому он не был нужен, и других путей у него не было. В том же году компания начала кормить союзнические и свои войска этим мясом, а англичане употребляли это мясо даже после войны, во время кризиса. Спам стал неизбежным и ужасным, вкус был мерзким, но людям ничего не оставалось и они все равно покупали его, чтобы хоть как-то выживать и тратить меньше денег на продукты [2].

3.Но на первое место среди английских слов к всеобщему удивлению вышло слово "plenipotentiary". Данным словом называют посла, который имеет много полномочий.

4.Понятие «bumf» означает скучную бумажную волокиту, которая задерживает человека на работе, или заставляет брать документы домой и работать дома.

5. Chuffed означает быть вне себя от удовольствия, так, что даже пыхтеть.

6. Если вдруг вы будете идти по дороге и захотите сойти с дороги на бордюр, непонятно почему, то это будет ваш whimsy. Или если иначе, то неожиданно появившийся причудливый каприз [2].

В опросе принимали участие лингвисты, являющиеся носителями различных языков, в том числе английского, французского, турецкого, украинского, китайского, дари, фарси, эфиопского, пушту, сомалийского и тамильского.

Из приведенных примеров можно сделать вывод, что новыми непереводимыми концептами выступают слова, связанные с данной культурой, национальным спортом, привычками и интернетом. Они, лучше некоторых учебников, помогут узнать суть и привычки того или иного народа.

$$
* * *
$$

1. http://admin.gorod.tomsk.ru

2. http://luckyfamilyman.ru

3. https://treewords.com

4. Cambridge Advanced Learner's Dictionary, 2016.

5. Мэлвин Брэгг. «Приключения английского языка.» Москва, 2014.

6. С.Г.Тер-Минасова. «Язык межкультурной коммуникации.» Москва, 2008. 